\title{
Toz Metalürjisi Yöntemi ile Üretilen Cu-Sn/Ni Kompozitinin Elektriksel İletkenliğine Isıl İşlemin Etkileri
}

\author{
Tülay YILDIZ*, Nida KATI, Nafiz BOZKURT \\ Firat Üniversitesi, Metalürji ve Malzeme Mühendisliği Bölümü, Elazı̆̆ \\ (ORCID: 0000-0001-9665-7733) (ORCID: 0000-0001-7953-1258) (ORCID: 0000-0002-9071-5813)
}

\begin{abstract}
Öz
Bu çalışmada, $\mathrm{Cu}-\mathrm{Sn}$ alaşımına $\% 3$ oranında Ni elementi ilave edilerek farklı sıcaklık ve basınçta, sabit sürede sıcak presleme yöntemi ile yeni matris malzemeler üretilmiştir. $\mathrm{Cu}$ ve alaşımları elektrik kontak malzemesi olarak geniş bir kullanım alanına sahiptir. $\mathrm{Bu}$ amaçla, $\mathrm{Cu}$ alaşımlarına ergime derecesi yüksek metal partikülleri ilave edilmiştir. Daha sonra ısıl işlem uygulanarak, üretilen malzemenin mekanik özellikleri arttırılmıştır. Böylece, malzemenin yüksek mukavemetli elektrik kontaklarında kullanılabilirliği araştıılmıştır. Elektrik kontaklarında gerçekleşen "aç-kapa" işlemleri ve ortaya çıkan arklar, pekleşme etkisi ve yeniden kristalleşme özelliklerini meydana getirmektedir. Bu etkiler göz önüne alınarak, çalışmamızda üretilen numuneler, pekleşme ve yeniden kristalleşme 1 sıl işlemlerine tabi tutulmuştur. Bu ssıl işlemlerin üretilen malzemelere ait mikroyapı, sertlik ve elektriksel iletkenlik özellikleri üzerine etkileri incelenmiştir. Yüzde iletkenlik, bütün numunelerde \%50 değerinin üzerinde elde edilmiş ve üretilen kompozitin iletken malzeme olarak sorunsuz bir şekilde kullanılabilir olduğu tespit edilmiştir.
\end{abstract}

Anahtar kelimeler: $\mathrm{Cu} / \mathrm{Sn}, \mathrm{Ni}$, sıcak presleme, 1 sll işlem, elektrik iletkenliği.

\section{Effects of Heat Treatment on Electrical Conductivity of Cu-Sn / Ni Composite Produced by Powder Metallurgy Method}

\begin{abstract}
In this study, by adding the $3 \% \mathrm{Ni}$ element to the $\mathrm{Cu}-\mathrm{Sn}$ alloy, new matrix materials have been produced by hot pressing method at different temperatures and pressures in a fixed time. $\mathrm{Cu}$ and its alloys have a wide usage area as electrical contact material. For this purpose, high melting metal particles are added to $\mathrm{Cu}$ alloys. Then, by applying heat treatment, the mechanical properties of the produced material were increased. Thus, the usability of the material in high-strength electrical contacts was investigated. The "on-off" processes in the electrical contacts and the arcs that arise create the strain harding effect and recrystallization properties. Considering these effects, the samples produced in our study were subjected to strain harding and recrystallization heat treatments. The effects of these heat treatments on microstructure, hardness and electrical conductivity properties of the produced materials were investigated. The percentage of the conductivity was obtained above $50 \%$ in all samples and it was determined that the produced composite can be used as conductive material without any problem.
\end{abstract}

Keywords: $\mathrm{Cu} / \mathrm{Sn}, \mathrm{Ni}$, hot pressing, heat treatment, electrical conductivity.

\section{Giriş}

Sıcak presleme, toz metalürjisinde de önemli bir yöntemdir. Katı durumdaki tozu tam yoğun parçalara dönüştürmekte kullanılır. Bu şekilde, geleneksel ergitme ya da presleme ve sinterleme üretim teknolojileriyle elde edilenden daha iyi fiziksel özellikler elde edilir. Metal tozlar, şekillendirilmiş sac metal içine hapsedilir ve net şekle yakın parçalar üretmek için sıcak presleme işlemine tabi tutulabilir. Gözenekler tamamen kapandığı zaman uygun bir yoğunluğa ulaşmak için parçalar sinterleme

*Sorumlu yazar: tyildiz@firat.edu.tr

Geliş Tarihi: 11.07.2020, Kabul Tarihi: 08.09.2020 
firınlarında ön sinterleme işlemine tabi tutulurlar [1, 2]. Yüksek mukavemet ve yüksek elektrik iletkenliğine sahip $\mathrm{Cu}$ alaşımları kurşun çerçeveler, konvektörler ve iletken yaylar gibi uygulamalar için önemli mühendislik malzemeleridir [3, 4]. Bununla birlikte, $\mathrm{Cu}$ alaşımlarında mukavemeti arttırmak için yaygın olarak kullanılan stratejiler, kaçınılmaz olarak, elektrik iletkenliğinin eşzamanlı olarak bozulması ile elektronların ek saçılımı ile sonuçlanan çözünen atomlar, çıkıklar, tane sınırları ve ikinci fazlar gibi kusurların ortaya çıkmasını içerir [3, 5]. TM uygulamalarının en çok kullanıldığı alanlardan biri de elektrik kontak malzemelerinin üretimidir. Kontak malzemeleri döküm, infilitrasyon ve toz metalürjisi gibi çeşitli yöntemlerle üretilebilmektedir. Fakat bu malzemelerde, yüksek elektriksel ve 1s1l iletkenlik, yüksek ergime sıcaklığı, yüksek korozyon ve yüksek ark aşınması direnci özelliklerinin hepsinin bir arada bulunmasının istenmesi üretim yöntemlerini kısıtlamaktadır. Örneğin; volframın çok iyi olan ısıl ve mekanik dayanım özellikleri ile bakırın muazzam elektrik iletkenliği özellikleri bir araya getirilip iyi bir kontak malzemesi üretmek istenmektedir. Fakat bakır-volfram bileşimli kontak malzemelerinin üretiminde, bakır ile volframın birbiri içerisinde çözünürlüğünün olmaması nedeniyle, ancak infilitrasyon veya toz metalürjisi yöntemleri tercih edilebilmektedir. Katı hal uygulamalarının başında gelen toz metalürjisinin diğer geleneksel ve ileri teknoloji metotlarına göre sağlamış olduğu avantajların en önemlisi, denge diyagramlarındaki şartların dışında hemen her tür malzemeye uygulanabilir olmasıdır. Toz metalürjisi yöntemiyle üretilmiş malzemelerin birçoğunu diğer geleneksel metotlarla üretmek hemen hemen imkânsız ya da çok güçtür [6, 7]. Modern teknolojinin sınırlılıklarından birisi de bazı metal alaşımlarının elde edilmesindeki zorluktur. Mesela, düşük ergime sıcaklığına sahip bir malzeme ile yüksek ergime sıcaklığına sahip diğer bir malzemeyi geleneksel tekniklerle alaşımlamak zordur. Böyle iki metal sıvı durumda çözelti oluşturmasına rağmen daha düşük ergime noktasına sahip olduğunda metal soğuma ve katılaşma yönünde ayrılır. Bunun yanında klasik üretim teknikleri ile üretilebilen malzemelerden daha sert, dayanıklı ve hafif malzemelere talebin artmasıyla yeni malzemelerin tasarımı ve geliştirilmesi söz konusu olmuştur $[6,8]$. Elektrik kontak malzemeleri, kayarak veya sabit temas sağlayarak elektrik devrelerini istenen zamanda açmak ve kapatmak için kullanılan metal esaslı parçalardır. Kontak malzemelerine evlerdeki aydınlatma tesisatının anahtarlarında ve her türlü elektrikli ev aletlerinde, endüstride özellikle otomasyonun vazgeçilmez bir parçası olan kondüktörlerde ve şalterlerde, otomobillerdeki elektrik aksamının kontrolü için kullanılan rölelerde ve yine endüstriyel amaçlı rölelerde vb. yerlerde rastlanmaktadır. Kontrollü bir elektrik devresinde kontakların birbiriyle teması sonucu devre enerjilenir ve akım akmaya baslar. Kontak malzemeleri açma-kapama ve kısa devre esnasında elektrik, termik, mekanik ve kimyasal yönden çok zorlanırlar. Kontaklar sürekli açılıp kapandığı için oluşan elektrik atlamaları (ark) zamanla kontakların oksitlenmesine ve iletkenlik özelliklerini kaybetmesine neden olur. Bu yüzden bir kontak malzemesinin çalışma süresince bütünlüğünü koruyabilmesi malzemenin yüksek elektriksel ve 1s11 iletkenliğine, yüksek ergime sıcaklığına, yüksek korozyon ve yüksek ark aşınması direncine de bağlıdır $[6,9]$.

Güler [10] yaptığı çalışmada çeşitli oksitleri, farklı oranlarda, içeren bakır tozları 5 saat süreyle planeter bilyeli değirmende öğ̈̈tülmek suretiyle mekanik olarak alaşımlandırmıştır. Mekanik alaşımlanan toz karışımlarını \%1, \%2, \%4 ve \%6 oranlarında $\mathrm{ZnO}, \mathrm{Al}_{2} \mathrm{O}_{3}$ ve $\mathrm{Y}_{2} \mathrm{O}_{3}$ ihtiva edecek biçimde hazırlanmıştır. Alaşımlama işleminden sonra bu tozlar preslenmiş ve vakum altında $800{ }^{\circ} \mathrm{C}$ 'de sentezlenmiştir. Yoğunluğu arttırmak için bu numuneler $650^{\circ} \mathrm{C}^{\prime}$ de $\% 75$ oranında dövülmüştür. En iyi iletkenliği belirlemek için bu numuneler üzerinde elektrik iletkenliği deneyleri yapılmıştır. Sonuçta, en iyi iletkenlik değerini \% 4 oksit takviyeli numunelerin sergilediğini belirlemiş ve daha sonra bu numunelerin kontak performansını tespit etmek için 3000, 6000 ve 9000 çevrim sayısında açma kapama deneyi uygulamıştır. Sonuç olarak hem en iyi iletkenliği hem de en iyi kontak performansını sırasıyla \%4 $\mathrm{ZnO}, \% 4 \mathrm{Al}_{2} \mathrm{O}_{3}, \% 4 \mathrm{Y}_{2} \mathrm{O}_{3}$ takviyeli bakır kontaklardan elde etmiştir. Altınsoy [11] yaptığ çalışmada toz metalürjisi yöntemiyle üretilen $\mathrm{Cu}_{-} \mathrm{Al}_{2} \mathrm{O}_{3}$ kompozitlerinin mikroyap1, mekanik ve elektriksel özelliklerine matris tane boyutu, takviye miktarı ve sinterleme sicaklığının etkisini incelemiştir. Bu doğrultuda iki farklı partikül boyutunda $(10 \mu \mathrm{m}$ ve $40 \mu \mathrm{m}) \mathrm{Cu}$ tozuna değişik oranlarda (ağ. \%1, 3, 5 ve 7) $\mathrm{Al}_{2} \mathrm{O}_{3}$ partikülleri $(0.3 \mu \mathrm{m}$ toz boyutunda) takviye edilmiş bakır tozları hazırlayarak, $200 \mathrm{MPa}$ basınçla presleme yaparak, kompozit kompaktları sırasıyla 875,925 ve $975^{\circ} \mathrm{C}$ olmak üzere üç farklı sicaklıkta 2 saat grafit tozuna gömülü halde sinterlemiştir. Sinterleme sonrası numuneleri yoğunluklarını arttırmak için $700 \mathrm{MPa}$ yük uygulayarak sıcak olarak dövmüştür. Takviye miktarının artışıyla tüm sinterleme sıcaklıklarında kompozitlerin elektriksel iletkenlikleri azalırken sertliklerinin arttığını tespit etmiştir. Bakır $(\mathrm{Cu})$ yüksek iletkenliği sayesinde elektrik kontak malzemesi olarak 
kullanılmaya uygundur. Fakat mekanik özelliklerinin; özellikle de sertliğinin düşük olması kullanım alanlarını sınırlamaktadır. Bu durum elektrik kontak endüstrisinde kullanılacak $\mathrm{Cu}$ için uygulama alanına göre katı eriyik veya oksit mukavemetlendirmesi işlemlerini zorunlu kılmaktadır $[6,10]$. Bakan, toz metalürjisi tekniği ile üretilen $\mathrm{Cu}-\% 25 \mathrm{Cr}$ kontak malzemesinin sinterleme davranışlarını incelemiştir. Ağırlıkça \% $74.5 \mathrm{Cu}, \% 25 \mathrm{Cr}$ ve $\% 0.5 \mathrm{Ni}$ içeren toz karışımı kullanarak sinterleme işlemi gerçekleştirmiştir. Sinterlenmiş numunelerde, teorik yoğunluğun \%98'i değerinde sinter yoğunluğu ile birlikte \%39 IACS elektrik iletkenliği değeri elde edilmiştir [12]. Gür vd. \%3 Ni takviyeli CuSn (85/15) Bronz alaşımının elektrik iletkenliğine sinterleme sıcaklığı ve sinterleme basıncının etkisini incelemişlerdir. Üretilen $\mathrm{Cu} / \mathrm{Sn} / \mathrm{Ni}$ kompozit numuneleri mikroyapı incelemeleri için hazırlayıp SEM ve EDS analizleri yaparak, numunelerden makrosertlik alınmıştır. Son olarak ise numunelerin elektrik iletkenlik değerleri öziletkenlik ve \%IACS değerleri ölçülmüştür [13]. Lopez vd., Cu esaslı kompozitler üreterek bu kompozitlerin iletkenlik değerlerini \%31.4 IACS (Uluslararası Tavlı Bakır Standardı, \%100 IACS $=58 \mathrm{MS} / \mathrm{m}$ ) olarak belirlemişlerdir [14]. Wieser vd. $\mathrm{Cu}-\mathrm{Sn}$ lehim sisteminde saf $\mathrm{Cu}, \% 1 \mathrm{Ni}$ ve $\% 3 \mathrm{Ni}$ substrat malzemeleri kullanarak farklı tavlama sıcaklıklarında intermetalik fazların oluşumunu belirlemişlerdir [15].

Bu çalışmada $\mathrm{Cu} / \mathrm{Sn}$ Bronz alaşımına Ni ilave edilerek farklı sıcaklık ve basınçta sıcak presleme yöntemiyle yeni matris malzemeler üretilmiştir. Cu esaslı metaller iyi elektrik özellikleri, ucuz olmaları ve üretim kolaylıklarından dolayı elektrik kontak malzemesi olarak tercih edilirler. Elektrik kontaklarında gerçekleşen "aç-kapa" işlemleri ve ortaya çıkan arklar, pekleşme etkisi ve yeniden kristalleşme özelliklerini meydana getirmektedir. Bu amaçla üretilen numunelere pekleşme ve yeniden kristalleşme 1sıl işlemleri uygulanmıştır ve ısıl işlemlerin üretilen malzemelere ait mikroyap1, sertlik ve elektriksel iletkenlik özellikleri üzerine etkileri incelenmiştir.

\section{Materyal ve Metot}

Bu çalışmada, 85/15 Bronz $(\mathrm{Cu} / \mathrm{Sn})$ alaşımına \%3 oranında Ni katılarak yeni bir matris malzeme üretilmiştir. Numune üretimi literatür çalışmaları doğrultusunda 20 ve $30 \mathrm{MPa}$ sinterleme basıncı, 700 ve $800^{\circ} \mathrm{C}$ sinterleme sıcaklığ 1 ve 15 dakika sinterleme süresi ile sıcak presleme yöntemiyle gerçekleştirilmiştir. Numunelerin üretim parametreleri Tablo 1'de gösterilmiştir. Numune üretiminde kullanılan metal tozların tane boyutları ise Tablo 2'de gösterilmiştir.

Tablo 1. Numune üretim Parametreleri

\begin{tabular}{|c|c|c|c|c|c|}
\hline Grup No & $\begin{array}{c}\text { Sinterleme Basınc1 } \\
\text { (MPa) }\end{array}$ & $\begin{array}{c}\text { Sinterleme Sicaklığ } 1 \\
\left({ }^{\circ} \mathrm{C}\right)\end{array}$ & $\begin{array}{c}\begin{array}{c}\text { Sinterleme Süresi } \\
(\mathrm{dk})\end{array} \\
\end{array}$ & $\begin{array}{c}\text { Bronz } \\
(\%)\end{array}$ & $\begin{array}{c}\text { Nikel } \\
(\%)\end{array}$ \\
\hline A-I & \multirow{2}{*}{20} & 700 & \multirow{4}{*}{15} & \multirow{4}{*}{97} & \multirow{4}{*}{3} \\
\hline A-II & & 800 & & & \\
\hline A-III & \multirow{2}{*}{30} & 700 & & & \\
\hline A-IV & & 800 & & & \\
\hline
\end{tabular}

Tablo 2. Numune üretiminde kullanılan metal tozlarının tane büyüklükleri Numune üretiminde kullanılan metal tozlarının tane büyüklükleri $(\mu \mathrm{m})$

\begin{tabular}{c|c}
\hline Bronz $(85 / 15)(\mathrm{Cu} / \mathrm{Sn})$ & Nikel (Ni) \\
\hline $70 \mu \mathrm{m}$ & $5 \mu \mathrm{m}$ \\
\hline
\end{tabular}

Numune üretimi için $\mathrm{Cu} / \mathrm{Sn}$ alaşımına \%3 Ni ilave edilerek homojen bir karışım elde etmek amacıyla turbula mikser kullanılmıştır. Karıştıııcı kapaklı toz hazneli ve 3 boyutlu dönebilen karıştırma mikserinden oluşmaktadır. $\mathrm{Cu} / \mathrm{Sn}$ alaşımına ilave edilecek tozların sıcak presleme öncesi belirli bir boyutta, mevcut profil yapısını koruyarak çalışılabilmesi için karışıma \%1 oranında Polietilen Glikol bağlayıcısı ilave edilmiştir. Hazırlanan metal tozları karıştırıcıda 20 dakika süreyle karıştırılmıştır. Homojen bir yapı elde edebilmek için karıştırma kovanına değişik çaplarda karışımının \%20'si oranında 
demir bilye ve zincir bırakılmıştır. Karıştırma işlemi gerçekleştirilen tozlar ön preslemesi yapıldıktan sonra, üretilecek numunelerin boyutlarına göre hazırlanmış grafit kalıplar içerisine alınarak sinterlemeye hazır hale getirilmiştir. Sinterleme işleminin daha sağlıklı olabilmesi için grafit kalıp, yağlayıcı ile yağlanmıştır. Numune üretimi sıcak presleme makinesinin basınçlı hidrolik ünitesi vasıtasıyla sağlanmaktadır. Sıcak pres makinesi; bakır elektrod, grafit elektrod, sıcak pres kalıbı, hidrolik silindir ve tutucu tabladan oluşmaktadır ve koruyucu gaz atmosferinde sinterleme işlemi yapılabilmektedir. Sicak pres makinesi su soğutmalı olup, bakır elektrotlar sayesinde sürekli çalışabilme özelliğine sahiptir. Sıcak presleme, 1sı ve basıncın aynı anda uygulanması ile gerçekleştirilmiştir. Isı ve basıncın aynı anda uygulanması ile tüm boşlukların tamamı veya tamamına yakını giderilir. Tüm partiküller arasında oluşacak üniform bir akış ile bağ kuvvetlenmiş olur. İşlemin sonunda Şekil 1'de görülen 10x10x40 mm boyutlarında numuneler üretilmiştir.

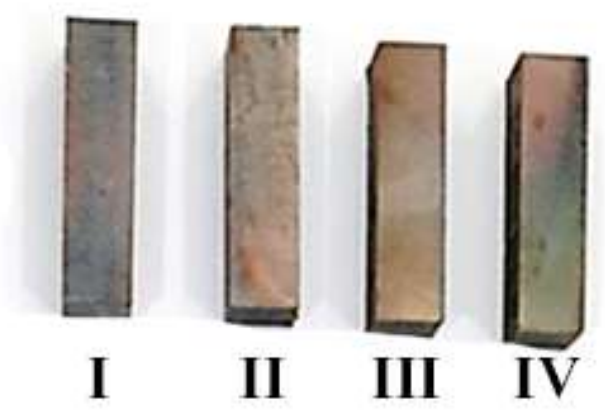

Şekil 1. Üretilen numuneler

Üretim aşaması tamamlanan numunelerin yüzeyleri metalografik incelemeler için hazırlanmıştır. Hazırlanan numunelerin mikro yapılarını incelemek amacı ile SEM görüntüleri alınmış ve üretilen numunelerdeki element miktarının tespiti için EDS analizi gerçekleştirilmiştir. Numunelerin sertlik ölçümleri "Emcotest Dura Scan" marka makro sertlik cihazıyla 62,5 kg yük ve 2,5 mm çapında bilye ile Brinell (HB) cinsinden gerçekleştirilmiştir. Sertlik ölçümleri için her bir numunenin bir yüzeyinden 5 tane brinel sertlik alınarak bu sertliklerin ortalama değerleri kullanılmıştır.

Pekleşme veya soğuk deformasyon sertleştirme bir metal güçlendirilmesi yöntemidir. Bu işlem dislokasyon hareketleri nedeniyle malzemenin kristal yapısı içinde oluşur. Bu şekilde sertleştirme, metaller ve alaşımlar gibi birçok malzemelere uygulanabilir. Pekleşme işlemi için numuneler 10x10x10 mm boyutlarında hazırlanıp dövülmüştür. Dövme işlemi $10 \mathrm{~kg}$ çekiç kullanılarak \%20 oranında şekil değiştirme sağlanacak şekilde gerçekleştirilmiş ve numune boyutları 10 mm'den 8 mm'ye indirilmiştir. Şekil 2'de pekleşme deneyinin şematik yapılışı görülmektedir.

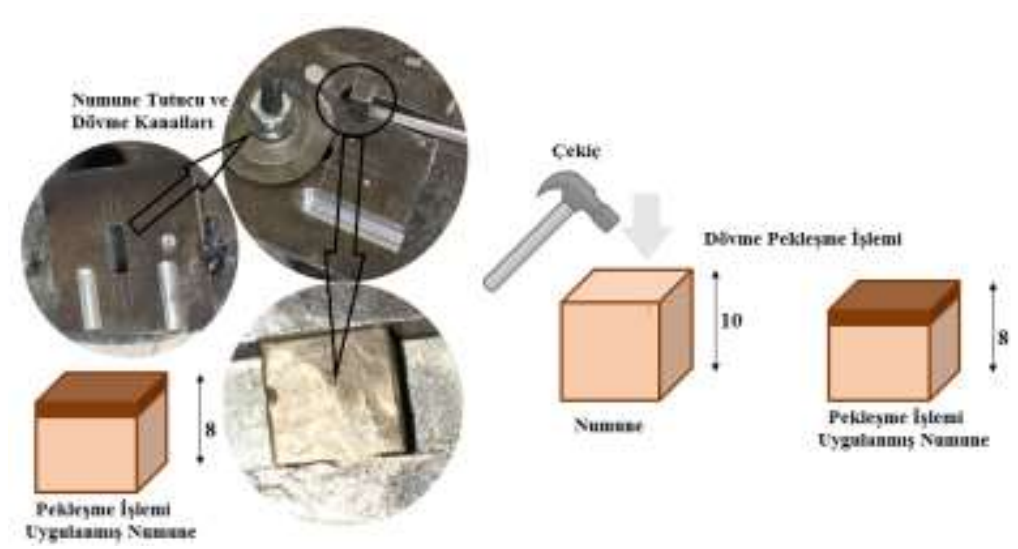

Şekil 2. Pekleşme işlemi şematik görüntüsü 
Pekleşme ile sertleştirilmiş malzemelerin veya plastik deformasyon güçlendirilmesi yapılmış malzemelerin dislokasyon hareketinin zorlaşması, metallerin, özellikle demir dışı metallerin sertlik ve mukavemetinin artmasına neden olur. Dolayısıyla dislokasyon sıkışması elektron hareketinin zorlaşması da alaşımlarda elektriksel iletkenliğin azalmasına neden olur. Bu olumsuzluğun giderilmesi için bu tip malzemelerin içyapılarının yeniden düzenlenerek mevcut özelliklerinin iyileştirilmesi gerekir. Bunun için soğuk deforme edilen malzemelere yeniden kristalleşme sıcaklığının (Te/3) üzerinde bir sıcaklık aralığında tavlama işlemi uygulanır [16]. Şekil 3'te yeniden kristalleşme tavı işleminde kullanılan, atmosfer korumalı firın görülmektedir. Yeniden kristalleşme deneyi $\mathrm{Cu} / \mathrm{Sn}$ alaşımının ergime derecesi olan $\mathrm{Te} / 3$ değerinde 5 saat süre bekletilerek yapılmıştır. $\mathrm{Cu} / \mathrm{Sn}$ alaşımının ergime derecesi faz diyagramı vasıtasıyla yaklaşık $880{ }^{\circ} \mathrm{C}$ civarında olduğu görülmektedir. Dolayısıyla yeniden kristalleşme sıcaklığı olarak $300{ }^{\circ} \mathrm{C}$ belirlenmiştir.

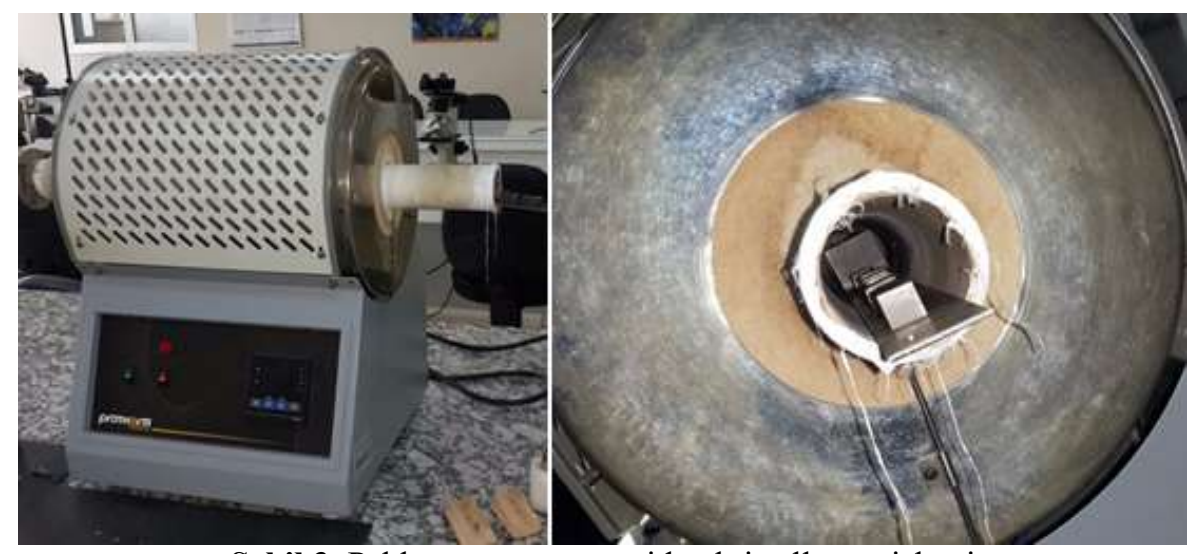

Şekil 3. Pekleşme sonrası yeniden kristalleşme işlemi

$\mathrm{Cu} / \mathrm{Sn}$ alaşımlarına $\% 3$ oranında Ni katılarak üretilen yeni matris malzemelerin, pekleştirme işlemi gerçekleştirilen numunelerin ve yeniden kristalleşme tavı uygulanan numunelerin elektriksel iletkenlik ölçümleri yapılmıştır. Doğru akım kullanılarak yapılan iletkenlik ölçümlerinde "Keithley 4200-SCS Semiconductor Characterization" markalı ölçüm cihazı kullanılmıştır. Numunelerin oda sıcaklığındaki direnç değerleri ölçülmüş ve birinci denklem yardımıyla öziletkenlik değerleri hesaplanmıştır. Ayrıca numunelerin \% IACS (International Annealed Copper Standart) değerleri de hesaplanmıştır. \% IACS değeri, tam yoğun tavlanmış saf bakırın öziletkenliğinin \%100 kabul edilmesi ile yapılan iletkenlik ölçüm standardı olup \%100IACS=58 MegaSiemens $/$ metre (MS/m)'dir. Dolayısı ile numunelerin \%IACS değerleri; eşitlik (2) yardımı ile hesaplanmıştır [6].

Öziletkenlik değeri $\sigma(\mathrm{m} / \Omega \times \mathrm{mm} 2)$, (1) eşitliği kullanılarak şu şekilde hesaplanabilir:

$$
\begin{aligned}
& \sigma=\frac{L}{R A} \Rightarrow L=d, \quad R=\frac{V}{I}, \quad A=\pi r^{2} \\
& \sigma=\left(\frac{I}{V}\right) \cdot\left(\frac{d}{\pi r^{2}}\right)
\end{aligned}
$$

Burada $d$ iki probe arası mesafeyi, $A$ alanı ve $r$ ise probun yarıçapını göstermektedir. $R$ direnç değerini, $V$ gerilim değerini ve $I$ ise akım değerini göstermektedir. Yapılan deneylerde $d$ ve $r$ parametreleri sırasıyla $0,4 \mathrm{~cm}$ ve $0,5 \mathrm{~mm}$ olarak işleme alınmıştır.

\%IACS değeri eşitlik (2) kullanılarak şu şekilde ifade edilir:

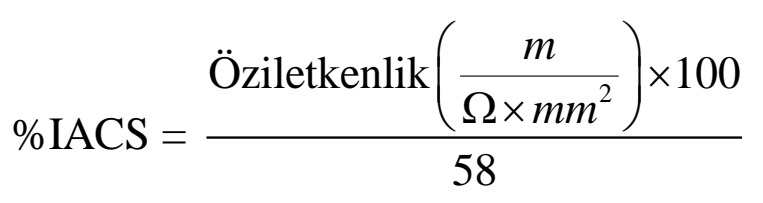




\section{Bulgular ve Tartışma}

A-I numunesine yapılan EDS analizi Şekil 4'te verilmiştir, $\mathrm{Cu} / \mathrm{Sn}$ alaşımına \%3 Ni ilave edilerek üretilen numunelerin mikroyapıları ise Şekil 5'te verilmiştir. $\mathrm{Bu}$ numunelerin resimleri " $\mathrm{x}$ " indisiyle gösterilmiştir. Aynı zamanda I ve II nolu numuneler $20 \mathrm{MPa}$ basınçta preslenmiş, III ve IV nolu numuneler ise $30 \mathrm{MPa}$ basınçta preslenmiştir. Aynı şekilde I ve III nolu numuneler $700{ }^{\circ} \mathrm{C}$ 'de, II ve IV nolu numuneler ise $800{ }^{\circ} \mathrm{C}$ 'de sinterlenmiştir.

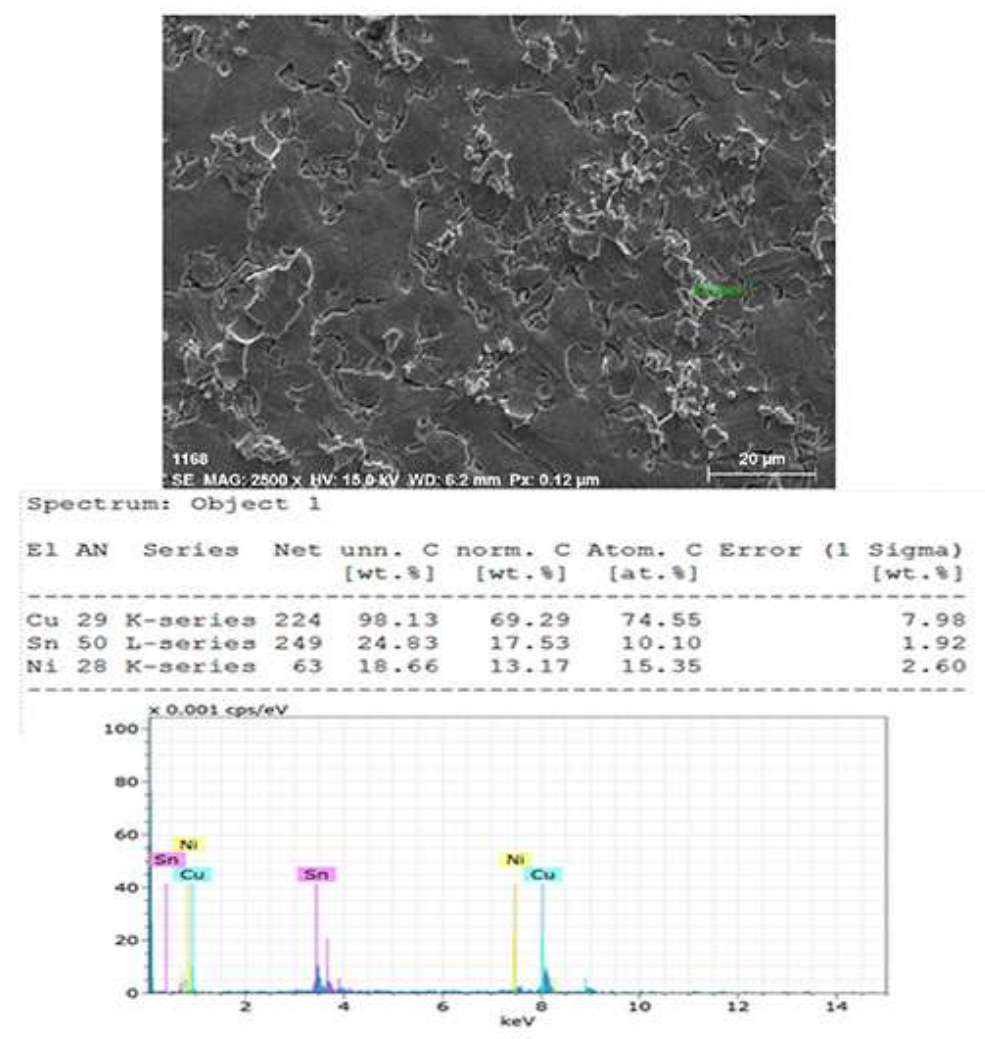

Şekil 4. A-I (x) numunesinin EDS analizi

Mikroyapılar incelendiğinde bütün numunelerde üretim parametrelerine uygun şekilde yapılar oluştuğu tespit edilmiştir. Basınç ve sıcaklığın artmasıyla daha homojen bir dağılım gözlemlenmiştir. Tane yapısı daha belirginleşmiştir. Üretim parametrelerimizin $20 \mathrm{MPa}$ ve $30 \mathrm{MPa}$ olduğu düşünülerek ve sinterleme yani sicak preslemede uygulanan sicaklık değerleri olan $700^{\circ} \mathrm{C}$ ve $800^{\circ} \mathrm{C}$ gibi sicaklikların da $\mathrm{Cu} / \mathrm{Sn}$ alaşımının ergime derecesinin altında olmasından dolayı bu ikizlenme çizgilerinin oluştuğu görülmüştür. EDS analiz sonucu incelendiğinde alaşım elementleri $\mathrm{Cu}$, Sn ve ilave element olan $\mathrm{Ni}$ dişında elemente rastlanmamıştır.

$\mathrm{Cu} / \mathrm{Sn}$ alaşımına \%3 Ni ilave edilerek üretilen numunelerin \%20 küçülme şeklinde ki pekleşme sonrası mikroyapıları Şekil 6'da gösterilmiştir. Bu numunelerin resimleri "y" indisiyle gösterilmiştir. Mikroyapılar incelendiğinde pekleşme uygulanan yüzeyde ve numune merkezinde herhangi bir çatlak görülmemektedir. Kompozit malzemede sadece partiküller arasında çok ince bir çizgide difüzyonla bağlanmış yapılar mevcuttur. Yani alaşım gibi üretiminin herhangi bir aşamasında; alaşımı oluşturan metallerden en az birisinin sıvı faza geçmiş olması ilkesi sıcak presleme veya toz metalürjisi imalat üretim teknolojisinde mevcut değildir. Dolayısıyla; yani pekleşme sırasında uygulanan darbelerle $\mathrm{Cu} / \mathrm{Sn}$ alaşımı ve Ni takviye elemanlarının kompozit içinde oluşturdukları bağ yapısında bir değişime sebep olması beklenmektedir. Resimler, numunelerin özellikle pekleşme uygulanan yüzeyinin olduğu yönden alınmaya özen gösterilmiştir. Bütün resimlerin üst yönü pekleşme yüzeyidir. Tüm numunelerin aynı metalografik incelemeye tabi tutulduğu düşünülürse, numunelerin pekleşen yönünde renk değişimi rahatlıkla görülmektedir. Pekleşme bir tabaka şeklinde oluşmuş numune boyunca devam etmemiştir. Pekleşme bölgesinde taneler daha sıkılaşmış ve dövme yönüne dik doğrultuda tanelerde yönlenme olduğu görülmüştür. 

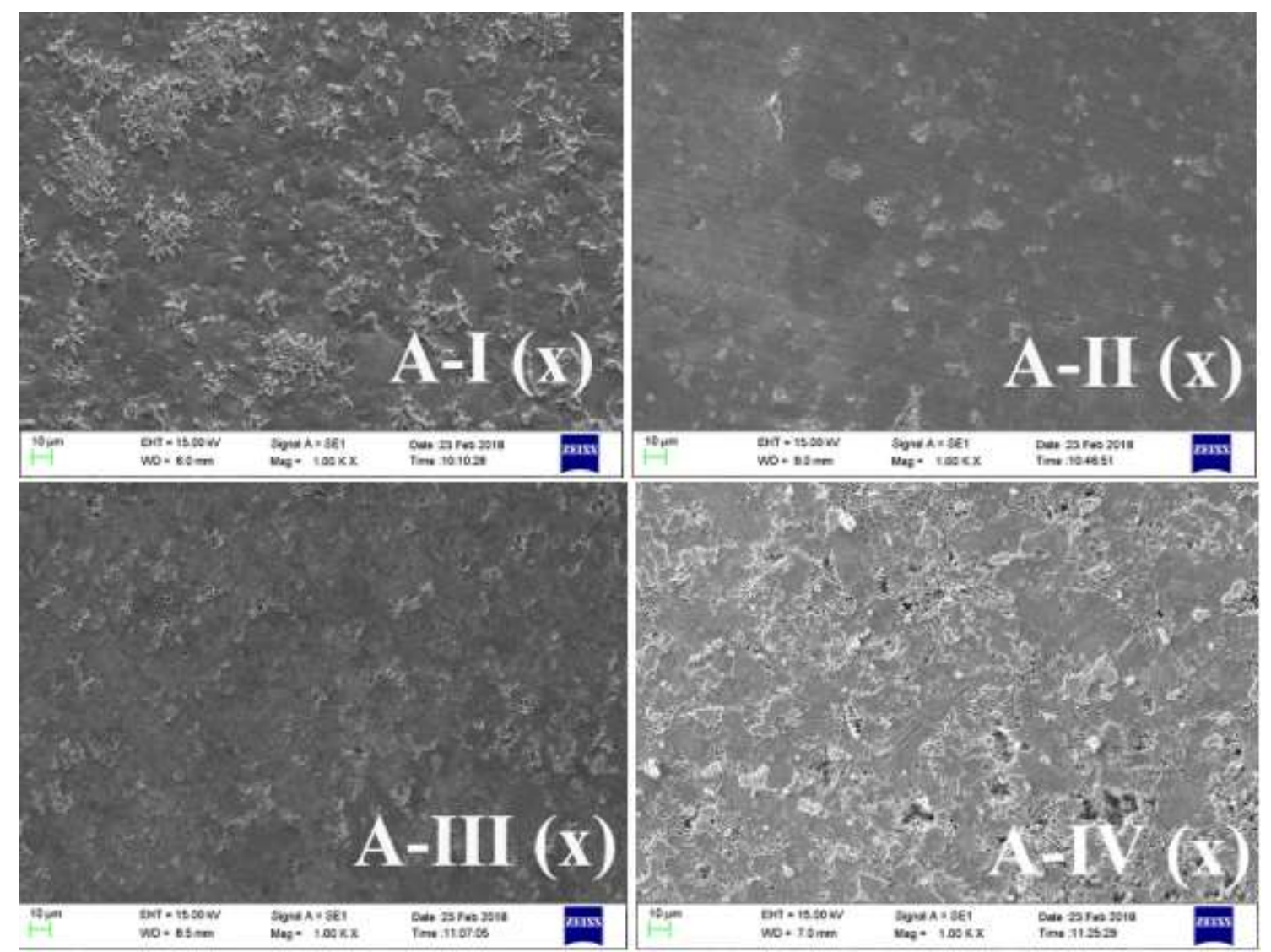

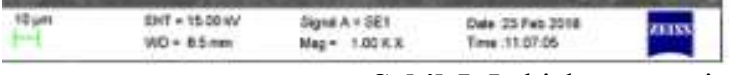

Şekil 5. Isıl işlem öncesi numunelerin mikro yapıları

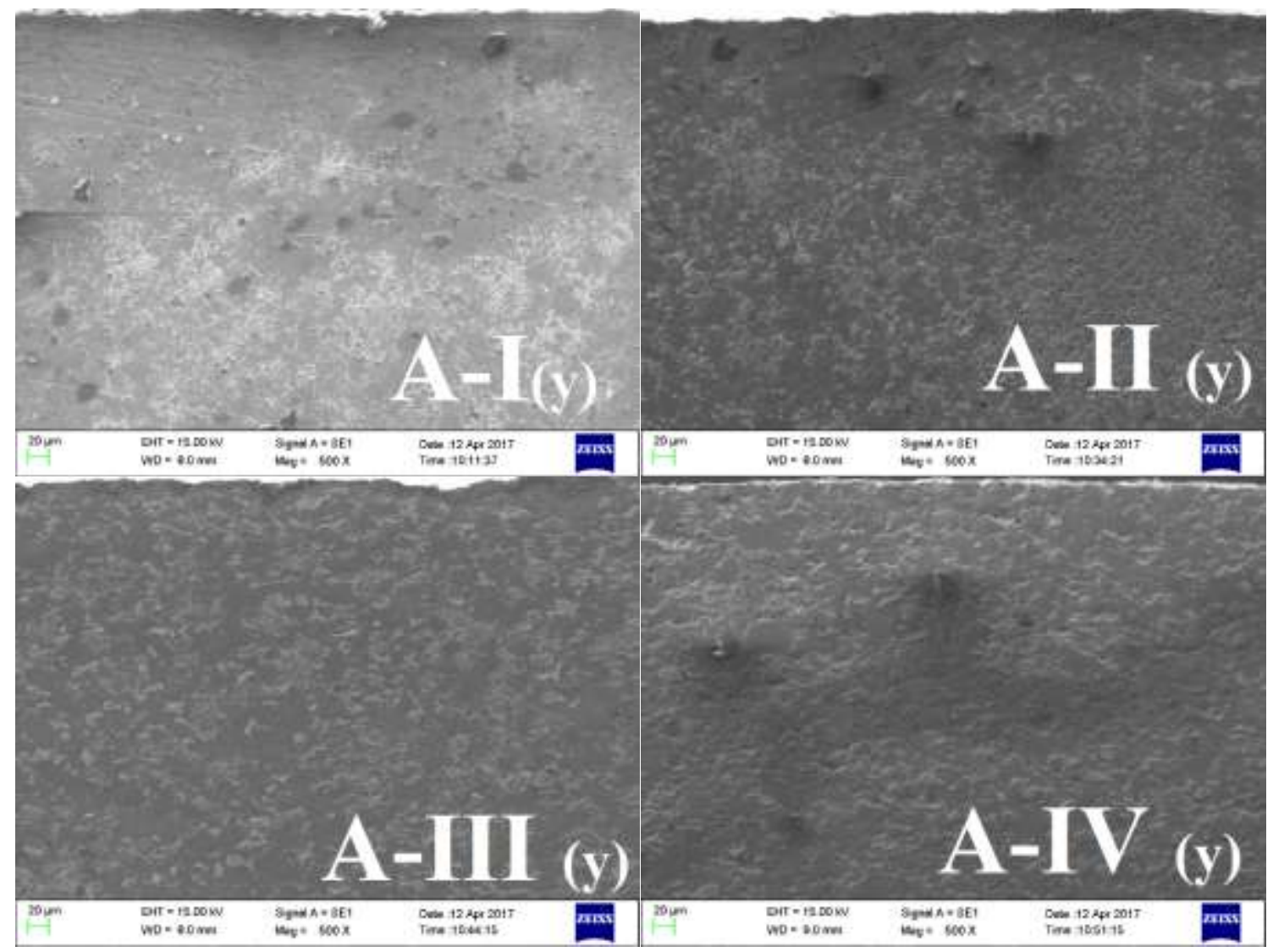

Şekil 6. Numunelerin pekleşme sonrası mikro yapıları 

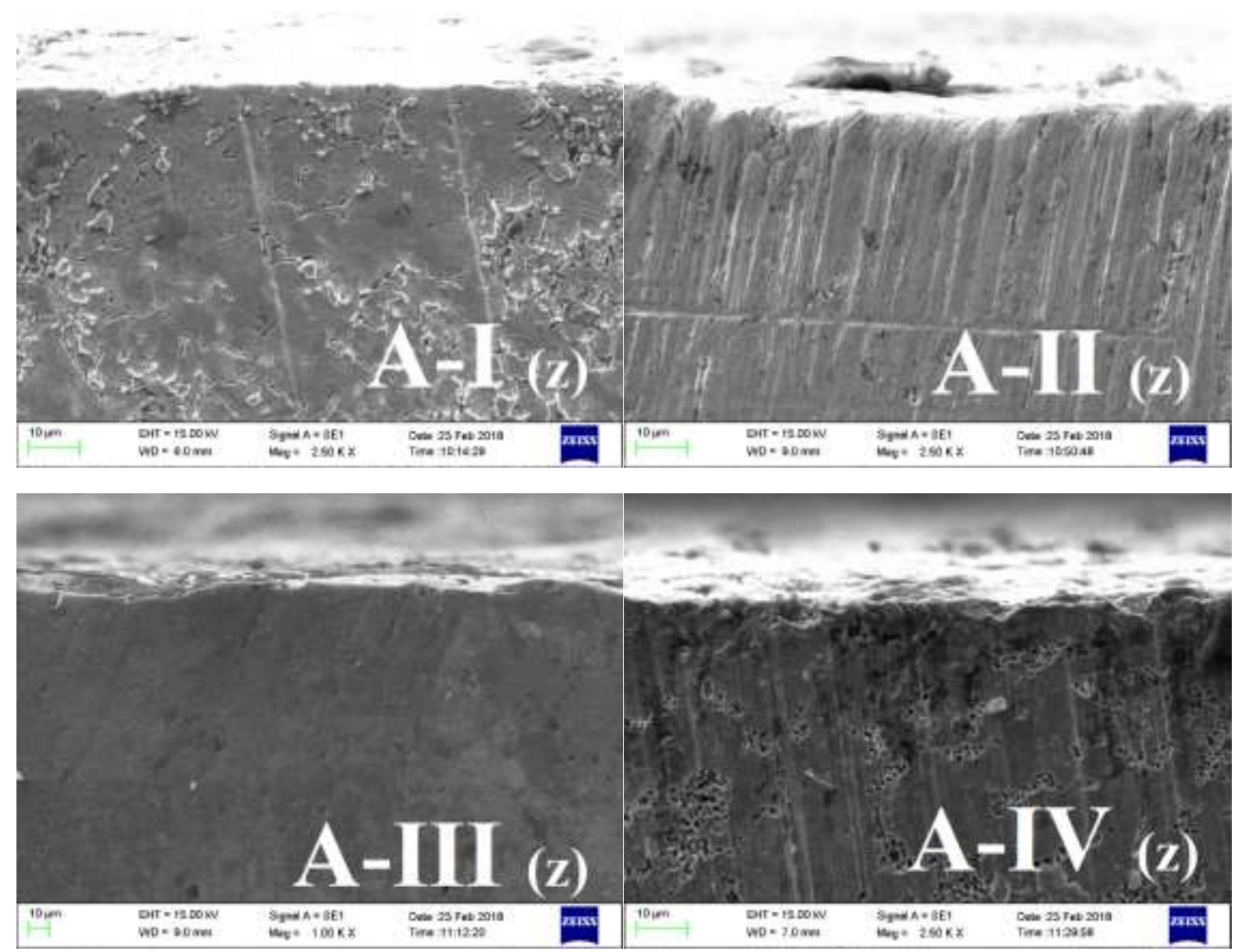

Şekil 7. Numunelerin yeniden kristalleşme sonrası mikro yapıları

$\mathrm{Cu} / \mathrm{Sn}$ alaşımına $\% 3 \mathrm{Ni}$ ilave edilerek üretilen numunelerin yeniden kristalleşme sonrası mikroyapıları Şekil 7'de gösterilmiştir. Bu numunelerin resimleri " $z$ ” indisiyle gösterilmiştir. Resimler numunelerin özellikle pekleşme uygulanan yüzeyinin olduğu yönden alınmaya özen gösterilmiştir. Pekleşme sonrasında yeniden kristalleşmenin yeniden meydana gelebilmesi için en az \%2-8' den daha yüksek oranda plastik deformasyona maruz kalması gerekir. Dolayısıyla bizim çalışmamızda da, $\mathrm{Cu} / \mathrm{Sn}$ bronz alaşımı için \%20 oranındaki plastik deformasyon sonrası yeniden kristalleşmenin başlaması beklenen bir durumdur. Yeniden kristalleşme için gerekli enerji büyük ölçüde deformasyon oranına bağlıdır. Yeniden kristalleşme sicaklığı değil, sıcaklık aralığını ifade eder. Yeniden kristalleşme sıcaklığı ergime sıcaklığının 1/3'ü kadar olacak şekilde hesaplanır. Yeniden kristalleşmeden sonra pekleşme sonrası yapıda oluşan artık gerilmeler büyük ölçüde giderilir. Dolayısıyla deformasyon sertleşmesi azalır. $\mathrm{Bu}$ durum dislokasyon sayısının azalmasından kaynaklanır. Dislakosyonların düzelmesinden dolayı elektron hareketi kolaylaşarak alaşım halindeki malzemenin elektrik iletkenliği normale döner. Artık gerilmeler kalkar ve dolayısıyla gerilmelerden kaynaklanan çarpılmalar en aza iner [16]. Yeniden kristalleşme sonucu oluşan taneler, alaşımların üretimi esnasındaki ilk tane yapısına döner. Ancak bu durum kompozit malzemede değerlendirilirken mikro büyüklükteki partiküller arasında oluşan difüzyon noktaları için değerlendirilebilir. Çünkü bizim çalışmamamızdaki numuneler alaşım değil kompozittir. Her ne kadar yoğunluk dereceleri alaşım hali kadar iyi olmuş olsa da taneler arası bağ yapısı için aynı durum söz konusu değildir ve olamaz. Yeniden kristalleşme sonrasında, pekleşmeden kaynaklanan partikül-tane yönlenmeleri üzerindeki artık gerilmeler kalkmış ve tanelerdeki bu eş yönlenmiş yapılar toparlanarak eski hallerine dönmeye çalışmışlardır. Mikroyapı fotoğraflarına bakıldığında (Şekil 7) pekleşme etkisinin kalktığı ve tekrar tane yapılarının oluştuğu görülmektedir. 


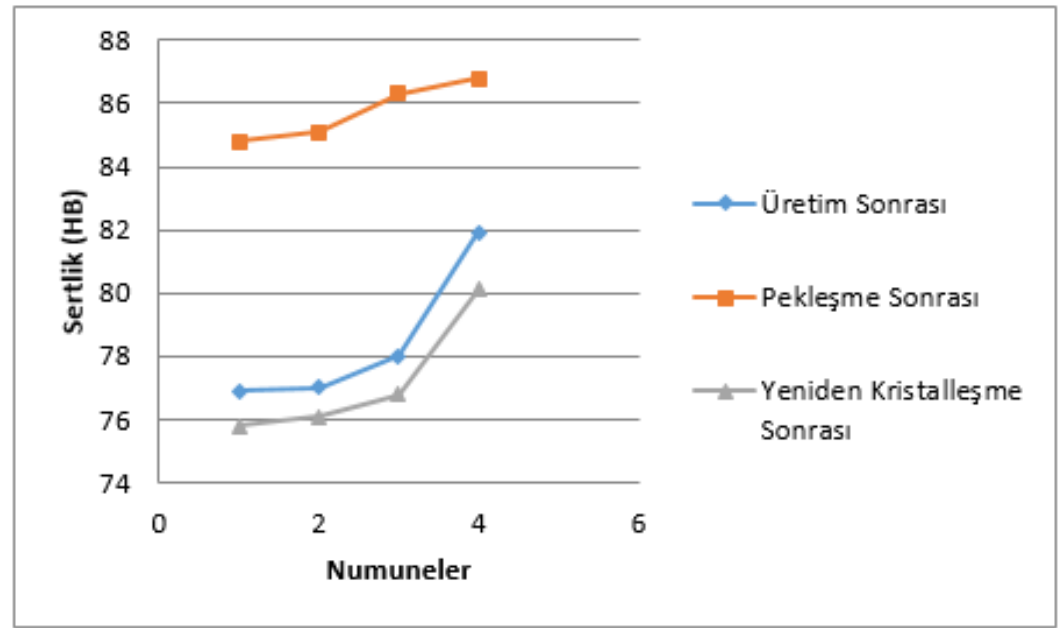

Şekil 8. Numunelerin sertlik değerleri

Tablo 3. Numunelerin Brinel Sertlik Sonuçları

\begin{tabular}{c|c|c|c}
\hline Gruplar & $\begin{array}{c}\text { Üretim Sonrası } \\
(\mathrm{HB})\end{array}$ & $\begin{array}{c}\text { Pekleşme Sonrası } \\
(\mathrm{HB})\end{array}$ & $\begin{array}{c}\text { Yeniden Kristalleşme } \\
\text { Sonrası (HB) }\end{array}$ \\
\hline A-I & 76,9 & 84,8 & 75,8 \\
\hline A-II & 77,0 & 85,1 & 76,1 \\
\hline A-III & 78,0 & 86,3 & 76,8 \\
\hline A-IV & 81,9 & 86,8 & 80,1 \\
\hline
\end{tabular}

Numunelerin sertlik değerleri brinel sertlik ölçme metoduyla alınmıştır. Bu amaçla, öncelikle numuneleri ürettikten sonra sertlikler ölçülmüş, ardından pekleşme işleminden sonra numunelerin sertliği pekleşen yüzeyden ölçülmüş ve en son da yeniden kristalleşme tavı uygulanmış numunelerin sertliği pekleştirilen yüzeyinden olacak şekilde ölçülmüştür. $\mathrm{Cu} / \mathrm{Sn}$ alaşımına $\% 3 \mathrm{Ni}$ ilave edilerek üretilen numunelerin sertlik ölçüm sonuçları birbiriyle kıyaslanarak değerlendirilmiştir. Şekil 8 ve Tablo 3 'te numunelerin sertlik grafiği ve sertlik değerleri görülmektedir. Tablo 3 ve Şekil 8'den görüldügü üzere, sıcaklık ve presleme basıncı arttıkça malzemedeki sertlik değeri de artmaktadır. Aynı şekilde pekleşme de aynı doğrultuda sertliğin artmasına sebep olmaktadır. Pekleşme sonrasında malzemedeki yoğunluğun artmasından dolayı sertlik değerleri artış göstermektedir. Pekleşmeden sonra numunelerde artık gerilmeler oluşur. Dolayısıyla deformasyon sertleşmesi olur. Bu durumun kompoziti oluşturan toz partikülleri arasında kalan boşlukların sayısının azalmasından kaynaklandığı düşünülmektedir. $\mathrm{Bu}$ çalışmada ki numuneler değerlendirilirken mikro büyüklükteki partiküller arasında oluşan difüzyon noktaları için değerlendirilebilir. Grafik incelendiğinde sertliklerin pekleşme işlemi sonrasında arttı̆̆ görülmektedir. Yeniden kristalleşme sonucu ise artık gerilmeler kalkar ve dolayısıyla gerilmelerden kaynaklanan çarpılmalar en aza iner, sertlik değerleri de eski haline yakın değerlere döner. Bu durum Şekil 8'de açıkça görülmektedir.

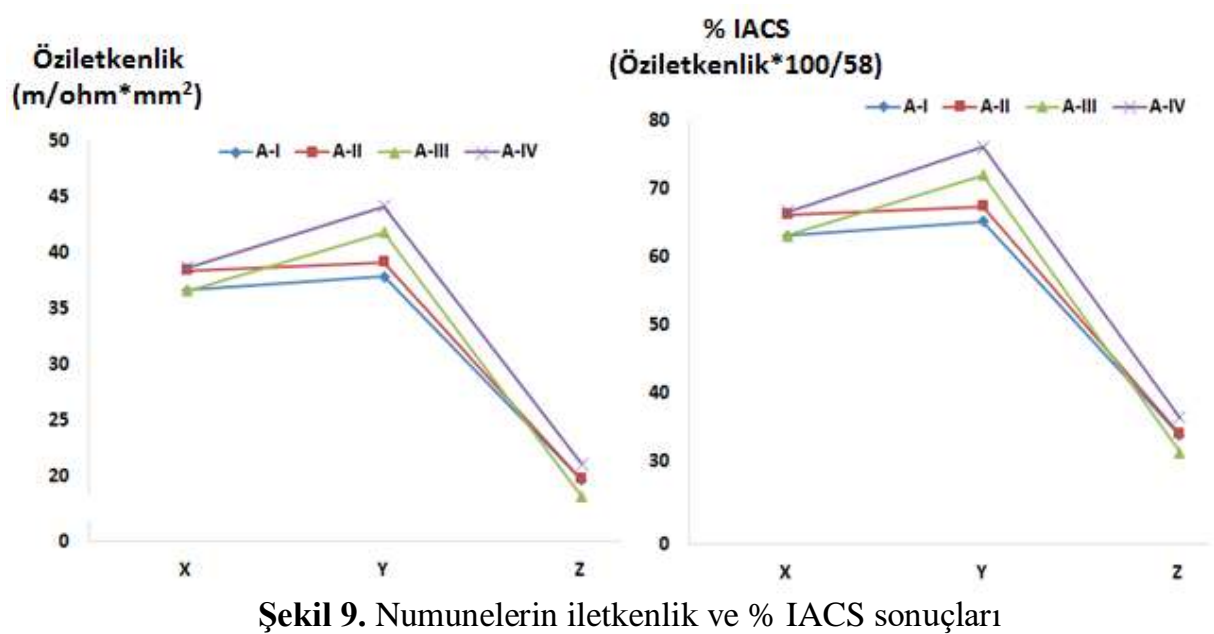


Tablo 4. Numunelerin iletkenlik ve \% IACS değerleri

\begin{tabular}{c|c|c|c|c|c|c}
\hline \multirow{2}{*}{ Numune } & \multicolumn{2}{|c|}{ Üretim Sonras1 } & \multicolumn{2}{c|}{ Pekleşme Sonras1 } & \multicolumn{2}{c}{$\begin{array}{c}\text { Yeniden Kristalleşme } \\
\text { Sonrası }\end{array}$} \\
\cline { 2 - 7 } & $\begin{array}{c}\text { Öziletkenlik } \\
\left(\mathrm{m} / \mathrm{ohm}^{*} \mathrm{~mm}^{2}\right)\end{array}$ & $\%$ IACS & $\begin{array}{c}\text { Öziletkenlik } \\
\left(\mathrm{m} / \mathrm{ohm}^{*} \mathrm{~mm}^{2}\right)\end{array}$ & $\%$ IACS & $\begin{array}{c}\text { Öziletkenlik } \\
\left(\mathrm{m} / \mathrm{ohm}^{*} \mathrm{~mm}^{2}\right)\end{array}$ & $\%$ IACS \\
\hline A-I & 36,5573 & 63,0299 & 37,7800 & 65,1378 & 19,6395 & 33,8611 \\
\hline A-II & 38,3378 & 66,0996 & 39,0556 & 67,3372 & 19,7297 & 34,0166 \\
\hline A-III & 36,5468 & 63,0117 & 41,7345 & 71,9559 & 18,1758 & 31,3375 \\
\hline A-IV & 38,5664 & 66,4938 & 44,1013 & 76,0368 & 21,1096 & 36,3957 \\
\hline
\end{tabular}

Üretim sonrası test edilen iletkenlik sonuçlarında; $\mathrm{Cu} / \mathrm{Sn}$ alaşımına $\mathrm{Ni}$ ilave edilmesiyle referans malzeme $\mathrm{Cu}$ elementine göre iletkenliklerde bir düşüs meydana gelmiştir. Üretilen malzemenin $\mathrm{Cu} / \mathrm{Sn}$ alaşımını ve kompozit özellikte olması ve Ni de iletkenlik özelliklerinin düşük olması kompozit malzeme bünyesindeki elektron hareketlerine ve dislokasyon hareketlerinin kısık olmasın neden olur [6]. Bu durum Altınsoy [11]'un çalışması ile de uyuşmaktadır.

Pekleşme sonrası test edilen iletkenlik sonuçlarında ise iletkenlik değerlerinde artış görülmüştür. Normal şartlarda oda sicaklığında $\mathrm{Cu}$ veya $\mathrm{Cu}$ alaşım iletkenlik değerleri ölçülmüş olsa bu durumun aksine düşüş beklenirdi. Çünkü iletkenlik pekleşme sonrası yapıdaki difüzyon hareketini kısıtlamakta ve dolayısıyla iletkenliğin de düşmesine sebep olmaktadır. Ancak üretilen numuneler toz metalürjisi ile üretilen kompozit malzeme olduğu için alaşım özellikleri göstermezler. Numunelere uygulanan pekleşme (soğuk deformasyon) işlemi sonrasında mikro boyutta toz partikülleri arasındaki boşlukların azaldığ1 ve yoğunluğun daha da arttı̆̆ düşünülmektedir. Bu sebepten iletkenlik değerlerinde artış görülmektedir.

Yeniden kristalleşme sonrası ölçülen iletkenlik ölçüm sonuçlarında ise iletkenliklerin ilk değerlerine yaklaşması beklenirken daha da düşüş görülmüştür. Bu durumun, soğuk deformasyon sonrasında numunelerin dövme bölgelerinde oluşan dislokasyon yoğunluğunun, yeniden kristalleşme sonrasında toparlanmasıyla, partiküller arasında difüzyon ve tane oluşumu sonrasında boşlukların artmasından kaynaklandığı düşünülmektedir. Çünkü yapıdaki süreksizlikler (boşluk, çatlak ve artık gerilme gibi) mevcut konumlarını kaybetmeleri sonucunda partiküller arası boşlukların büyümesine sebep olur.

İletkenlik IACS grafikleri incelendiğinde (Şekil 9) bütün numunelerde aynı mekanizmayı gösteren eğrilerin çıkması düşüncelerimizi desteklemektedir. İletkenlik test referans numunesi $\mathrm{Cu}$ elementinin iletkenlik değeri $52 \mathrm{MS} / \mathrm{m}$ iken; ürettiğimiz numunelerin iletkenliklerinin hiçbiri bu değere ulaşamamıştır. En yüksek iletkenlik değeri A-IV numunesinde üretim sonrasında 38,5664 MS/m olarak ölçülmüştür. A-IV numunesinin IACS değeri ise \%66,4938 hesaplanmıştır. Şekil 9 ve Tablo 4 'te iletkenlik ve \%IACS değerlerine ait grafik ve sonuçlar verilmiştir. \%IACS değeri, tam yoğun tavlanmış saf bakırın öz iletkenliğinin \%100 kabul edilmesi ile yapılan iletkenlik ölçüm standardı olup \%100 IACS $=58 \mathrm{MegaSiemens} /$ metre' dir [14].

Şekil 9'dan anlaşılacağı üzere en yüksek IACS değeri pekleşme sonrası elde edilen yapılara aittir. Yeniden kristalleşme sonrası bu değerler düşmektedir. Bakır esaslı alaşımların yüksek sıcaklıklardaki iletkenlik uygulamaları için istenilen en az iletkenlik değerinin \%50 IACS olduğu bilinmektedir. Dolayısıyla çalışmadaki numuneler iletkenlik açısından değerlendirildiğinde ürettiğimiz $\mathrm{Ni}$ takviyeli $\mathrm{Cu} / \mathrm{Sn}$ alaşımının elektrik yükleri altında çalıştığında kontak malzemesi olarak kullanılmasının uygun olduğu düşünülmektedir. Soğuk deformasyon sonrası numunelerin öziletkenlik değerleri ve \%IACS değerlerinin arttığı grafiklerde görülmektedir. Numunelere ait ölçülen \%IACS değerinin tamamı standart olarak kabul edilen \%50 IACS değerinin üzerinde çıkmıştır. Yeniden kristalleşme sonrasında ise numunelerin öziletkenlik değerleri ve \%IACS değerlerinin düştüğü grafiklerde görülmektedir. Numunelere ait ölçülen \%IACS değerinin tamamı standart olarak kabul edilen \%50 IACS değerinin altında çıkmıştır. Elektrik devresinde ki şalterlerin her aç kapa işlemi sonrasında, çenelerin vuruş ve sonrasında oluşacak ark ile ortaya çıkacak ısının yapıyı bozabileceği aşikârdır. Ancak iletkenlik olayının şalter kapalıyken yani çekiç vurması sonrası olduğu düşünülürse de bu defa iletkenlik açısından oldukça iyi sayılabilecek değerler ölçülmüştür [6]. 


\section{Sonuç ve Öneriler}

Bu çalışmada sıcak presleme yöntemi ile $\mathrm{Cu} / \mathrm{Sn}$ alaşımına \%3 Ni ilave edilerek; 20 ve $30 \mathrm{MPa}$ sinterleme basinc1, 700 ve $800^{\circ} \mathrm{C}$ sinterleme sicaklığ ve 15 dakika sinterleme süresinde yeni numuneler üretilmiştir.

Üretilen numunelerin SEM fotoğrafları incelendiğinde, üretim parametrelerine uygun şekilde yapılar oluştuğu tespit edilmiştir. Basınç ve sıcaklığın artmasıyla daha homojen bir dağılım gözlemlenmiş ve tane yapıları daha belirginleşmiştir. Pekleşme deneyi sonrası mikroyapılarda, pekleşme bir tabaka şeklinde oluşmuş ve numune boyunca devam etmemiştir. Pekleşme bölgesinde taneler daha sıkılaşmış ve dövme yönüne dik doğrultuda tanelerde yönlenme olduğu görülmüştür. Yeniden kristalleşme sonrası mikroyapılarda, pekleşmeden kaynaklanan partikül - tane yönlenmeleri üzerindeki artık gerilmelerin kalktığı düşünülerek tanelerdeki eş yönlenmiş yapılar toparlanıp eski hallerine dönmeye çalışmışlardır.

Sertlik sonuçları incelendiğinde; sıcaklık ve presleme basıncı arttıkça malzemedeki sertlik değerleri artmıştır. Pekleşme deneyi sonrasında da malzemedeki yoğunluğun artmasından dolayı sertlik değerleri artış göstermiştir. Yeniden kristalleşme sonucu ise artık gerilmelerin kalktığı düşünülerek gerilmelerden kaynaklanan çarpılmalar en aza inmiştir böylece sertlik değerleri de üretim sonrası sonuçlara yakın değerlere dönmüştür.

Üretim sonrası test edilen iletkenlik sonuçlarında; $\mathrm{Cu} / \mathrm{Sn}$ alaşımına $\mathrm{Ni}$ ilave edilmesiyle referans malzeme $\mathrm{Cu}$ elementine göre iletkenliklerde bir düşüş meydana gelmiştir. Numunelere uygulanan pekleşme deneyi sonrasında iletkenlik değerlerinde artış görülmüştür, yeniden kristalleşme sonrası iletkenlik ölçüm sonuçları iletkenliklerin ilk değerlerine yaklaşması beklenirken düşüş göstermiştir.

Çalışmadaki numuneler iletkenlik açısından değerlendirildiğinde ürettiğimiz Ni takviyeli $\mathrm{Cu} / \mathrm{Sn}$ alaşımının elektrik yükleri altında çalıştığında kontak malzemesi olarak kullanılmasının uygun olduğu düşünülmektedir. Uygulanan isıl işlemler açısından bakıldığında da pekleşme sonrası numunelerin kontak malzemesi olarak kullanılması uygundur.

\section{Teşekkür}

$\mathrm{Bu}$ çalışma Fırat Üniversitesi Bilimsel Araştırma Projeleri TEF.17.01 nolu proje tarafindan desteklenmiştir.

\section{Yazarların Katkısı}

Tüm yazarlar bu makalenin yazılmasında eşit katkı sağlamışlardır.

\section{Çıkar Çatışması Beyanı}

Yazarlar arasında herhangi bir çıkar çatışması bulunmamaktadır.

\section{Araştırma ve Yayın Etiği Beyanı}

Yapılan çalışmada, araştırma ve yayın etiğine uyulmuştur.

\section{Kaynaklar}

[1] "Wire manufacturing and free sintering with NEXT®." [Online]. Available: https://www.researchgate.net/publication/292870049_Wire_manufacturing_and_free_sintering_ with_NEXTR. (Access date: 08.07.2020).

[2] "Hot Consolidation of Powders \& Particulates." [Online]. Available: https://www.techstreet.com/standards/hot-consolidation-of-powdersparticulates?product_id=1910910. (Access date: 08.07.2020).

[3] Zeng W., Xie J., Zhou D., Fu Z., Zhang D., Lavernia E.J. 2018. Bulk Cu-NbC nanocomposites with high strength and high electrical conductivity. J. Alloys Compd., 745: 55-62. 
[4] Ghosh G., Miyake J., Fine M.E. 1997. The systems-based design of high-strength, highconductivity alloys. JOM, Minerals, Metals and Materials Society, 49 (3): 56-60.

[5] "On the Influence of Temperature on the Electric Conducting-Power of Alloys," 1863. [Online]. Available: https://www.amazon.com/Influence-Temperature-Conducting-Power-PhilosophicalTransactions/dp/B01AGVP336. (Access date: 08.07.2020).

[6] Gök M.G. 2010. $\mathrm{B}_{2} \mathrm{O}_{3}$ Katkı1ı Kontak Malzemesi Üretimi ve Özelliklerinin Araştırılması. Yüksek Lisans Tezi, Fırat Üniversitesi, Fen Bilimleri Enstitüsü, Elazı̆̆.

[7] Bostan B. 2003. Alüminyum-Karbon Tozlarından Mekanik Alaşımlama ve Sonrası işlemlerle A14C3 Sentezlenmesi. Doktora Tezi, Gazi Üniversitesi, Fen Bilimleri Enstitüsü, Ankara.

[8] Suryanarayana C. 2001. Mechanical alloying and milling. Progress in Materials Science, 46 (12): 1-184.

[9] Güler Ö., Evin E. 2009. The investigation of contact performance of oxide reinforced copper composite via mechanical alloying. J. Mater. Process. Technol., 209 (3): 1286-1290.

[10] Güler Ö. 2006. Oksit Takviyeli Bakır Kompozitin Mekanik Alaşımlama Yöntemi ile Üretilmesi ve Elektriksel Özelliklerinin İncelenmesi. Yüksek Lisans Tezi, Fırat Üniversitesi, Fen Bilimleri Enstitüsü, Elazı̆̆.

[11] Altınsoy İ. 2009. Alümina Takviyeli Bakır Kompozitlerin Üretimi ve Karakterizasyonu. Yüksek Lisans Tezi, Sakarya Üniversitesi, Fen Bilimleri Enstitüsü, Sakarya.

[12] Bakan H.İ. 1999. Toz Metalurjisi Yöntemi ile Üretilen Cu-\%25 Cr Elektrik Kontak Malzemesinin Sinterleme Davranışlarının İncelenmesi. Doktora Tezi, İstanbul Teknik Üniversitesi, Fen Bilimleri Enstitüsü, İstanbul.

[13] Gür A.K., Yıldız T., Bozkurt N. 2019. 85/15 Bronz Kompozitinde Ni İlavesinin Üretim Parametrelerinde Elektriksel İletkenliğe Etkisi. DÜMF Mühendislik Derg., 10 (3): 981-988.

[14] López M., Corredor D., Camurri C., Vergara V., Jiménez J. 2005. Performance and characterization of dispersion strengthened $\mathrm{Cu}-\mathrm{TiB} 2$ composite for electrical use. Mater. Charact., 55 (4-5): 252-262.

[15] Wieser C., Hügel W., Martin S., Freudenberger J., Leineweber A. 2020. Stabilization of the $\zeta$ Cu10Sn3 Phase by Ni at Soldering-Relevant Temperatures. J. Electron. Mater., 49 (6): 36093623.

[16] Callister W.D. 2003. Malzeme Bilimi ve Mühendisliğii (Materials Science and Engineering). John Wiley \& Sons, Inc. 